\title{
Oscillometric Blood Pressure Monitor
}

National Cancer Institute

\section{Source}

National Cancer Institute. Oscillometric Blood Pressure Monitor. NCI Thesaurus. Code C69319.

An instrument for blood pressure monitoring consisting of a sphyg momanometer and an electronic pressure sensor (transducer) that detects blood flow by the presence of ocillations in the cuff pressure. 